\title{
Ethical behaviour among registered and non-registered counsellors
}

Nurul Hasyimah Mat Rani ${ }^{1,2, *}$, Wan Marzuki Wan Jaafar ${ }^{1}$,Sidek Mohd Noah ${ }^{1}$

${ }^{1}$ Department of Counsellor Education and Psychology Counselling, Faculty of Educational Studies, Universiti Putra Malaysia, Selangor, Malaysia

${ }^{2}$ Department of Psychology and Counselling, Faculty of Education and Human Development, Sultan Idris Education University, Tanjung Malim, Malaysia

\section{A R T I C L E IN F O}

\section{Article history:}

Received 1 November 2016

Received in revised form

7 January 2017

Accepted 8 January 2017

\section{Keywords:}

Ethical behaviors

Counsellors

Counselling ethics

Registered counsellors

\begin{abstract}
A B S T R A C T
This study seeks to identify whether or not there is a difference in the ethical behaviour of registered counsellors and non-registered counsellors. This study also seeks to identify if there is a difference between ethical behaviour based on the demographic factors of age, gender, experience and qualification of the counsellors. The study design adopted is the ex-post facto design. The study sample comprises of 355 registered counsellors and nonregistered counsellors all over Malaysia. The study tool employed is Ethics Practice Survey adapted by previous research. The analyses used are the Ttest and the One-Way ANOVA. The study results show that registered counsellors have more ethics if compared to their non-registered counterparts. Next, the study results also demonstrate that there is a significant difference between the ethical behaviour of counsellors according to their age, gender, experience and qualification of counsellors. The implications of the study are also elaborated.

(C) 2017 The Authors. Published by IASE. This is an open access article under the CC BY-NC-ND license (http://creativecommons.org/licenses/by-nc-nd/4.0/).
\end{abstract}

\section{Introduction}

The career as a counsellor is increasingly recognised in Malaysia with the enactment of the Counsellor Ethics Code and Counsellor Act 1998 (Act 580). There are various career opportunities as counsellor in public and private organisations such as Guidance and Counselling Teacher at schools, Psychology Officer (Counsellor) in various ministries nationwide, counsellors at higher learning institutes, defence institutes, hospitals and various private organisations.

Professional counsellors are counsellors who practise counselling in an ethical manner. They are often exposed to various ethical issues when they conduct counselling practice such as multiple relationship issues (Smith and Smith, 2001), confidentiality issues, competency and expertise, professional relationships, abuse, value conflict (Elliot, 2011) and issues concerning various cultures. Clients who are present to get the assistance of counsellors also come from various backgrounds of race, religion, socio-economy and culture. This diversity has exacerbated the situation. The

\footnotetext{
* Corresponding Author.

Email Address: hasyimah@fppm.upsi.edu.my (N. H. M. Rani) https://doi.org/10.21833/ijaas.2017.03.021

2313-626X/C 2017 The Authors. Published by IASE.

This is an open access article under the CC BY-NC-ND license

(http://creativecommons.org/licenses/by-nc-nd/4.0/)
}

complexity and the uniqueness of every issue raised by clients in the counselling session can make counsellors act in a way that is unethical like exposing the particulars of clients to the third party without his or her consent. The unethical practice can become detrimental to the client emotionally, physically and spiritually.

\section{Literature review}

Counsellors in Malaysia can be divided into two categories-Counsellors who have registered with the Board of Counsellors known as Registered Counsellors (KB) and counsellors who have yet to register or better known as Non-registered Counsellors. Counsellor registration is vital so that all counsellors in Malaysia obtain the certification as Registered Counsellors. By not registering legally counsellors can be subjected to the violation of the law and they have conducted an unethical practice (Act 580). In Malaysia there are still a lot of counsellors who have yet to register with the Malaysian Board of Counsellors. Up until March 2016 , only 6350 counsellors have registered and are acknowledged as "Registered Counsellors". The Board of Counsellors has been working hard to encourage counsellors all over Malaysia to register.

However, not all counsellors can register themselves as Registered Counsellors. They need to fulfil the minimum requirement at the Bachelor's 
Degree level such as having sufficient curriculum credit which is a minimum of 81 credit hours and at the Master Degree level a minimum of 48 credit hours encompassing core subjects, practical training and practicum, internship and elective subjects and research project. According to the Act, individuals violating sub-section 1 can be subjected to imprisonment for a maximum of 3 years and maximum fine of RM30 thousand or both. Thus, counsellors cannot take lightly their registration as counsellors because it is their obligation to register. Without this registration, individuals cannot call themselves counsellors and they cannot perform any services as counsellors in any public or private organisations.

According to the Deontology Theory, ethical behaviour is a behaviour done by an individual to fulfil his or her tasks based on certain standards in an orderly manner (Knapp and VandeCreek, 2007). Ethical Behaviour is also a self-reporting by a respondent whether or not he or she is involved in certain behaviour (Swenson et al., 2009). This study seeks to identify the behaviour of counsellors in the counsellors' ethical practice. The objective of this study is to identify the difference of the ethical behaviour based on age, gender and experience of counsellors. Other than that, this study also has the intention to identify the difference of ethical behaviour between registered counsellors and nonregistered counsellors all across Malaysia.

\section{Methodology}

This study is a quantitative study that measures the difference between ethical practice among registered and non-registered counsellors all over Malaysia including Sabah and Sarawak. This study employs the Ethic Practice Questionnaire adapted by Gibson and Pope (1993). This questionnaire measures 9 constructs namely i) not becoming detrimental; ii) practice with expertise; iii) not exploiting (sexual and physical touch issues; iv) not exploiting (financial, fees and accepting gift); v) not exploiting (multiple relationship issue, other multiple relationship also advertising and obtaining clients); vi) treating respectfully and with dignity; vii) protecting confidentiality; viii) acting only by consent; and $\mathrm{x}$ ) encouraging equality and fairness. The study respondents were chosen through the simple random sampling method. The total number of respondents is 355. From that, there are 226 Registered Counsellors and 129 non-registered counsellors. Questionnaires were distributed to the respondents involved and they are analysed using SPSS 22.0. Researchers employ the Independent Ttest and One Way ANOVA in this study.

\section{Results and discussion}

To determine the difference of the demographic factors (age, gender, experience and qualification) towards the dependent variable (counsellors' ethical behaviour), the analyses of Independent T-Test and One-Way ANOVA are adopted.

\subsection{Ethical behaviour based on the age}

Ho1 (i): There is no significant difference between age and ethical behaviour of the counsellors in Malaysia.

Table 1 and Table 2 show the summary of OneWay ANOVA of the difference of counsellors' ethical behaviour according to respondents' age. The study finding shows that the mean score for the respondents according to age is between 21 to 30 years $($ Mean $=52.35, \mathrm{SD}=4.48), 31$ to 40 years $($ Mean $=52.34, \mathrm{SD}=4.15), 41$ to 50 years (Mean $50.18, \mathrm{SD}=5.21$ ) and 51 years and above (Mean = $48.18, \mathrm{SD}=4.96$ ). The study findings further show that the null hypothesis is rejected. There is a significant difference between the age of respondents and ethical behaviour where the value of $F(3,351)=9.25, p=0.000(p<0.05)$. This shows that the counsellors' ethical behaviour differs according to their age.

Table 1: Summary of difference between age and behaviour of counsellors in Malaysia

\begin{tabular}{ccc}
\hline Age & Mean Difference & Standard Deviation \\
\hline 21 to 30 & 52.35 & 4.48 \\
31 to 40 & 52.34 & 4.15 \\
41 to 50 & 50.18 & 5.21 \\
51 years $\geq$ & 48.18 & 4.96 \\
Total & 51.70 & 4.70 \\
\hline
\end{tabular}

Table 2: Summary of difference between the ethical behaviour of counsellors based on age

\begin{tabular}{cccccc}
\hline & Variance Difference & $\mathrm{df}$ & Mean Square & $\mathrm{F}$ & Sig. \\
\cline { 2 - 6 } Between Groups & 573.36 & 3 & 191.12 & 9.25 & 0.000 \\
Within Group & 7250.57 & 351 & 20.65 & & \\
Total & 7823.94 & 354 & & & \\
\hline \multicolumn{7}{c}{ Significant at confidence level $\mathrm{p}<0.05$} \\
\hline
\end{tabular}

\subsection{Ethical behaviour based on the gender}

Ho1 (ii): There is no significant difference between ethical behaviour based on the gender of the counsellors in Malaysia (Table 3 and Table 4).
The Independent Sample T-Test is done to identify the difference between the gender of the respondents and the ethical behaviour of the counsellors in Malaysia. The study finding illustrates that there is a significant difference between the ethical behaviour of male counsellors (Mean $=50.60$, 
$\mathrm{SD}=4.55)$ and the ethical behaviour of female counsellors (Mean $=52.20, \mathrm{SD}=4.69)(\mathrm{t}=-3.009, \mathrm{df}=$

$$
353, p=0.003, p<0.05) \text {. }
$$

Table 3: Summary of difference of ethical behaviour based on the gender of the counsellors

\begin{tabular}{ccccc}
\hline & Gender & $\mathrm{N}$ & Mean & Standard Deviation \\
\cline { 2 - 5 } Ethical & Male & 111 & 50.60 & 4.55 \\
Behaviour & Female & 244 & 52.20 & 4.69 \\
\hline
\end{tabular}

Table 4: Summary of difference of ethical behaviour of counsellors based on gender

\begin{tabular}{|c|c|c|c|c|c|}
\hline & \multicolumn{2}{|c|}{ Levene Test } & \multirow{2}{*}{$\mathrm{t}$} & \multirow{2}{*}{ df } & \multirow{2}{*}{ Sig. (2-Tailed) } \\
\hline & $\mathrm{F}$ & Sig & & & \\
\hline Equal variances assumed & 0.012 & 0.914 & -3.009 & 353 & 0.003 \\
\hline Equal variances not assumed & & & -3.042 & 218.666 & 0.003 \\
\hline
\end{tabular}

\subsection{Ethical behaviour based on their experiences}

Ho1 (iii): There is no significant difference between ethical behaviour based on counsellors' experiences in Malaysia.

Table 5 and Table 6 give us a summary of OneWay ANOVA on the difference of ethical behaviour of counsellors according to their experiences in the counselling field. The study finding shows that the mean score for respondents with experience between 1 and 5 years is (Mean $=52.02$, SD $=4.11$ ), 6 to 10 years $($ Mean $=52.58, \mathrm{SD}=4.21), 11$ to 15 years (Mean $=51.16, \mathrm{SD}=4.90), 16$ years and above (Mean $=47.40, \mathrm{SD}=6.46)$, and no experience (Mean $=50.92, \mathrm{SD}=5.88)$. The finding further shows that the null hypothesis is rejected. There is a significant difference between the experience and ethical behaviour of counsellors in Malaysia $F(4,350)=$ 5.95, $\mathrm{p}=0.000(\mathrm{p}<05)$.

\subsection{Ethical behaviour of registered and non- registered counsellors}

Ho5 (i): There is no significant difference between the ethical behaviour of registered and nonregistered counsellors in Malaysia (Table 7 and Table 8).

The Independent Sample T-Test is done to identify the difference between the counsellors' registration status in their ethical behaviour. The finding shows that there is a statistical difference between the ethical behaviour of registered counsellors (Mean $=52.23, \mathrm{SD}=4.40)$ and nonregistered counsellors $($ Mean $=50.77, \mathrm{SD}=5.06$ ) with t value $=2.735, \mathrm{df}=237.17, \mathrm{p}=0.007, \mathrm{p}<0.05$ ). The null hypothesis is rejected. Result shows that the ethical behaviour between the registered and nonregistered counsellors has a significant difference.

Table 5: Summary of the difference of ethical behaviour based on counsellors' experience in Malaysia

\begin{tabular}{ccc}
\hline Year of Experience & Mean Difference & Standard Deviation \\
\hline 1 day-5 years & 52.02 & 4.11 \\
6 Years-10 Years & 52.58 & 4.21 \\
11 Years-15 Years & 51.16 & 4.90 \\
16 Years $\geq$ & 47.40 & 6.46 \\
No experience & 50.92 & 5.88 \\
Total & 51.70 & 4.70 \\
\hline
\end{tabular}

Table 6: Summary of difference between ethical behaviour based on the experience of counsellors

\begin{tabular}{cccccc}
\hline & Variance Difference & $\mathrm{df}$ & Mean Square & $\mathrm{F}$ & Sig. \\
\cline { 2 - 5 } Among Groups & 498.47 & 4 & 124.618 & 5.95 & 0.000 \\
In Group & 7325.473 & 350 & 20.93 & & \\
Total & 7823.94 & 354 & & \\
\hline \multicolumn{5}{c}{ Significant at confidence level $\mathrm{p}<0.05$}
\end{tabular}

Table 7: Summary of ethical behaviour between registered counsellors and non-registered counsellors

\begin{tabular}{ccccc}
\hline & Registration Status & $\mathrm{N}$ & Mean & Standard Deviation \\
\cline { 2 - 5 } Ethical Behaviour & Registered Counsellors & 226 & 52.23 & 4.40 \\
& Non-Registered Counsellors & 129 & 50.77 & 5.06 \\
\hline
\end{tabular}

Table 8: Summary of difference between registered counsellors and non-registered counsellors in terms of ethical behaviour

\begin{tabular}{ccccccc}
\hline & \multicolumn{2}{c}{ Levene Test } & $\mathrm{t}$ & $\mathrm{df}$ & Sig. (2-Tailed) \\
\cline { 2 - 3 } & $\mathrm{F}$ & $\mathrm{Sig}$ & & & \\
Equal variances assumed & 4.385 & 0.037 & 2.841 & 353 & 0.005 \\
Equal variances not assumed & & & & 2.735 & 237.175 & 0.007 \\
\hline
\end{tabular}

\section{Discussion and implication of study}

The study finding shows that the ethical behaviour differs according to age, gender and experience. Result shows that counsellors aged 21 to 30 years are dissimilar to the counsellors aged between 41 to 50 years and 51 years and above in terms of their ethical behaviour. Apart from that, counsellors aged between 31 to 40 years also show different ethical behaviour from counsellors aged 41 to 50 years and 51 years and above. There is a difference between male and female counsellors in their ethical behaviour. Mean score for female counsellors is higher than male counsellor. There is 
also a difference between the experience of counsellors between 16 years and above and counsellors with experience between 1 day to 5 years, 6 years to 10 years and 11 years to 15 years.

Our study finding shows that there is a difference in the ethical behaviour between registered counsellors and non-registered counsellors in Malaysia. Registered counsellors have higher mean of ethical behaviour compared to their non-registered counterparts. Counsellor Registration is vital for an individual called Counsellor, at par with several functions of the Board confined under Act 580 which is monitoring and supervising the counselling service delivered by the Counsellor and supervising his or her training, at the same time determining the type and level of counselling done in Malaysia.

The counselling field in Malaysia has its own standard to be fulfilled by the practitioners like taking part in a formal training under standard curriculum endorsed by the Board of Counsellors (Malaysia). With the enactment of the Counsellors Act 1998 (Act 580), the counselling field is endorsed and acknowledged as a professional service in Malaysia.

Counsellors who have no ethics can adversely affect the clients who will be in a session with them. A study done in China by Leung et al. (2003) showed those Counsellors at secondary schools have committed an unethical service in regard of the confidentiality of the clients. This has led counselling teachers in Hong Kong to not have any idea about keeping the information to the clients confidential when there are issues or conflicts concerning ethics arisen. This can become detrimental physically or emotionally to the clients in the future.

There are counsellors who still have not registered with the Malaysian Board of Counsellors. Since the year 2010, only 1746 counsellors who registered as Registered Counsellors and there is an increase to 6450 counsellors in 2016. There is also the curriculum requirement that has to be fulfilled by the counsellors at both Bachelor Degree and Master levels. The requirement has to be met so the in-service counsellors have the knowledge, skills and adequate training before they can be deemed qualified as professionals.

Ethical behaviour is often observed in any organisations, whether at schools, higher learning institutions, or public and private institutions. The work by Crall (2011) showed that there is one third of supervisors who disobey the ethical rules and regulations. Supervisors, as experienced educated individuals in the area of counselling can also commit ethical offences by violating the existing rules of ethics.

\section{Conclusion}

Ethical behaviour is indirectly a client's mandate to the customer. Clients who are seeking for a counselling service will put high hopes that the counsellor who would be able to help them is someone with good ethics. A counsellor has an ethical obligation that has to be executed so that a client's wellbeing can be safeguarded and to avoid the client from being endangered or negatively affected in any way. The Board of Counsellors has the role to observe the practice carried out by registered counsellors and by those who have certificate of practice. Should there be any conflict arising to the non-registered counsellors, for example if a client commits suicide, these nonregistered counsellors will not be protected by any legal bodies or agencies because they do not have any Registered Counsellor license and certificate. Thus, as a professional counsellor, the registration as registered counsellors is crucial, not only to the client, but also to the counsellors themselves and to the counselling profession. Automatically, by registering, counsellors have performed ethical behaviour and conduct legal counselling practice.

\section{References}

Crall J (2011). Ethical behavior of supervisors: Effects on supervisee experience and behaviour. Theses and Dissertation Paper, Lehigh University, Pennsylvania, USA.

Elliot GR (2011). When values and ethics conflict: The counselor's role and responsibility. Alabama Counseling Association Journal, 37(1): 39-45.

Gibson WT and Pope KS (1993). The ethics of counseling: A national survey of certified counselors. Journal of Counseling and Development, 71(3): 330-336.

Knapp S and VandeCreek L (2007). When values of different cultures conflict: Ethical decision making in a multicultural context. Professional Psychology: Research and Practice, 38(6): 660-666.

Leung SA, Leung TK, and Chan EPO (2003). Ethical counseling practice: A survey of counseling teacher in Hong Kong secondary schools. Asia Journal of Counselling, 10(1): 71-94.

Smith JA and Smith AH (2001). Dual relationships and professional integrity: An ethical dilemma case of a family counsellor as clergy. The Family Journal: Counseling and Therapy For Couple and Families, 9(4): 438-443.

Swenson III JE, Schneller GR, and Sanders RK (2009). Ethical issues in integrating Christian faith and psychotherapy: Beliefs and behaviors among CAPS members. Journal of Psychology and Christianity, 28(4): 302-315. 